\title{
The Effect of Text Messaging on EFL Learners' Lexical Depth and Breadth
}

\author{
Behnam Behforouz ${ }^{1}$, Anca Daniela Frumuselu² \\ ${ }^{1}$ University of Rovira i Virgili \\ ${ }^{2}$ University of Lleida \\ Correspondence concerning this article should be addressed to Behnam Behforouz, University of Rovira i \\ Virgili, Spain.E-mail: behnam.behforouz@estudiants.urv.cat

\begin{abstract}
Using technology in the classroom context can be an effective way to learn a foreign or second language. Vocabulary is considered one of the important skills for identifying a learner's performance in various academic and non-academic contexts. The present paper investigated the effect of text messaging on learners' lexical knowledge and vocabulary size by using mobile learning ( m-learning). After the administration of an Oxford Placement Test, a total of 37 EFL learners were selected as the sample of the study. Before the treatment process, a word association test (WAT) and the updated vocabulary level test (UVLT) were administered as pretests. The learners received six vocabulary items selected from their coursebook through SMSs three times a week in addition to the in-class instruction. After finishing the treatment process, the WAT and the UVLT tests were administered again as post-tests to assess the learners' achievement and the effectiveness of the treatment. Since the normality of data distribution was not confirmed, the Wilcoxon signed-rank test was run for mean comparisons. The findings showed no meaningful difference between the pre-tests and post-tests regarding the vocabulary depth scores, while there was a statistically significant difference based on vocabulary breadth. Therefore, it can be claimed that text messaging via m-learning had a significant impact on learners' vocabulary breadth. Curriculum developers and EFL teachers can benefit from the findings of the current study by considering the significance of text messaging for teaching different aspects of lexical knowledge.
\end{abstract}

Keywords: m-learning, text messaging, vocabulary breadth, vocabulary depth

\section{Introduction}

Due to the rapid development of science and technology, distance communication utilizing technology, especially wireless networks, has rapidly become ubiquitous. Mobile phones, as part of the current technologies and as multifunctional instruments, have become essential parts of our daily lives. The application of mobile technology has changed the way people communicate and interact with each other, as well as their perspective of education (Liaw, Hatala, \& Huang, 2010; Liu \& Chen, 2008). The widespread availability of these up-to-date devices with competitive prices has altered the process of mobile learning (m-learning) dramatically in many different ways (Farangi, Kamyab, Izanlu, \& Ghodrat, 2017).

As stated by Kukulska-Hulme (2013), mobile learning involves using any portable educational devices, such as portable radios, cell phones, audio cassettes, etc. in educational settings. Based on Alexander's (2004) definition, $\mathrm{m}$-learning is viewed as every sort of learning that occurs while mediating via a mobile device and has accepted the legitimacy of 'nomadic' students.

The fast growth of the English language learner (ELL) population should cause a modification in academic instruction and, therefore, the manner educators take into account the classroom context. ELLs create a heterogeneous cluster with a variety of racial, ethnic, cultural, linguistic, and socio-economic backgrounds, as well as theirstrengths and weaknesses. The cultural and linguistic variations affect the way ELLs learn the language and its related skills and sub-skills. Accordingly, preparing learners for their future in society requires teaching them how to create personal meaning by employing the knowledge they can use to communicate, learn, analyze, give a reason, evaluate, and be conveniently flexible by being able to easily adapt to various communicative situations in a wide range of settings. 
Through the growing application of communicative approaches in the teaching process, the need for an appropriate word list becomes evident in order to be accessible when learners make an attempt to communicate. Lexical knowledge is a substantial part of a foreign language. Without adequate lexical knowledge, communicative interactions can be hard to achieve. When individuals try to transfer a message, they may be capable of sending it with inadequate knowledge of structure, but it seems quite problematic to communicate a message with a lack of an appropriate level of basic lexical knowledge (Agdam \& Sadeghi, 2014).

There are multiple dimensions for lexical knowledge ranging from the lowest degree of knowledge (unfamiliar words) to the highest degree of perceiving the word (familiar words and their meanings). Paribakht and Wesche (1993, as cited in Mehrpour \& Montasseri, 2019) categorize lexical knowledge into the following steps:

1. Learners may have never faced the word before and cannot identify the word;

2. Learners may have heard the word but cannot define it;

3. Learners identify the word considering its context of use or voice tone, but their understanding of its meaning is not clear;

4. Learners understand the word meaning in general but are not able to explain its meaning clearly;

5. Learners can identify different meanings of the word and are able to use it fluently (p. 104).

Based on the findings of a large number of studies (Chapelle, 1998; Nation, 1990; Qian, 2002), lexical knowledge is a multidimensional construct (Henriksen, 1999; Kieffer \& Lesaux, 2012b; Read, 2000; Schmitt, 2014). Qian (2002) presents four distinctive classifications of lexical knowledge: (a) vocabulary breadth, (b) vocabulary depth, (c), automaticity of receptive-productive knowledge, and (d) lexical organization. However, Qian (1999), Wesche and Paribakht (1996), and Read (1989) acknowledge that lexical knowledge requires encompassing at least two aspects, i.e., vocabulary size or breadth and vocabulary quality or vocabulary depth. It should be mentioned that vocabulary size or breadth refers to the number of words a student knows, and vocabulary depth reveals how profoundly a student has knowledge of a word (Qian, 2005; Qian \& Schedl, 2004).

To learn the new vocabulary, different types of instructional aids are available to the students, among which mobile devices are one of the most popular and influential ones. Mobile phones can be considered helpful devices for learning and teaching because of their inclusive features such as «accessibility, personalizability, and portability» (Saran \& Seferoglu, 2010, p. 253), the physical aspects, input capabilities, output capabilities, the storage capacity and retrieval, the speed of the processor, and the «low+ error rates» (Alzu'bi \& Sabha, 2013, p. 179).

\section{Literature Review}

While reviewing the literature, it was noted that some of the studies that reported the application of mobile devices in vocabulary learning could be categorized as the use of SMS - MMS (Alemi, Sarab, \& Lari, 2012; Çavuş \& İbrahim, 2009; Hayati et al., 2013; Hu, 2013; Zhang, Song, \& Burston, 2011), the use of email (Thornton \& Houser, 2005), the use of some programs developed by individual researchers (Başoğlu \& Akdemir, 2010; Chen \& Chung, 2008; Stockwell, 2007, 2010), and the use of other mobile features (Ağca \& Özdemir, 2013; Dağdeler, Konca, \& Demiröz, 2020; Liu \& Chen, 2014). These studies have mainly suggested the positive effects of mobile device applications during the learning process. It was shown that the learners in experimental groups receiving instruction via mobile technology were more successful than those in the control groups studying through conventional methods (Başoğlu \& Akdemir, 2010; Hayati et al., 2013; Liu \& Chen, 2014; Lu, 2008, Zhang et al., 2011). Considering the learned vocabulary retention, some studies reported that there was not a notable difference between groups (Lu, 2008; Zhang et al., 2011) while others revealed that the use of SMSs provided retention of target vocabularies (Alemi et al., 2012; Saran, Seferoglu, \& Cagiltay, 2012).

\section{Lexical Knowledge}

The lexical knowledge is one of the main readers' variables that identifies language learners' performance on different kinds of tests. As Shen (2008) points out, vocabulary is a key component in language, and vocabulary learning has gained much attention in the English language teaching (ELT) research field. According to Schmitt (2008), lexical knowledge plays a major role, and one thing that learners, trainers, syllabus designers, and researchers can come to a consensus on is that vocabulary learning is an indispensable part of mastering an L2. 
Theoretically, distinguishing lexical knowledge may not be clear cut. A prominent framework for lexical knowledge was presented by Richards (1976), considering the seven dimensions of register, associations, frequency, form, meaning-concept, position, and meaning-associations. Later, Nation (1990) suggested eight types of lexical knowledge, determined both for productive and receptive knowledge, consisting of spoken form, written form, concept, associations, grammatical patterns, collocations, frequency, and appropriateness. Chapelle (1998) proposed four aspects of lexical knowledge: vocabulary size, the knowledge of word features, organization of lexicon, and vocabulary processes. Henriksen (1999) distinguished three aspects of lexical knowledge: knowledge of partial to precise, the depth of knowledge, and receptive to productive usability, and Qian (2002) classified four dimensions using the existing frameworks: vocabulary depth of knowledge, breadth of knowledge, automaticity of receptive-productive knowledge, and lexical organization. Despite a lack of agreement on the multidimensional nature of vocabulary knowledge, such a claim that this knowledge should have only two basic features, breadth (or size) and depth (or quality), appears to have been generally accepted (Anderson \& Freebody, 1981; Qian, 1999, 2002; Read, 1993; Wesche \& Paribakht, 1996). Alderson and Freebody (1981) wrote that the breadth aspect of lexical knowledge refers to the number of words that a speaker knows, while on the other hand, vocabulary depth refers to the understanding or quality of the words. The effect of these aspects of lexical knowledge has been mainly investigated in studies in the reading comprehension area (e.g., Kaivanpanah \& Zandi, 2009; Nassaji, 2004, 2006).Based on Aviad and Laufer (2013), lexical knowledge can be measured both qualitatively and quantitatively regarding depth and breadth of knowledge and strength of knowledge of meaning as well.

The depth aspect of vocabulary deals with paradigmatic and syntagmatic relations, which involve synonyms, superordinates, and collocations (Schoonen \& Verhallen, 2008). It is the quality of lexical knowledge that shows the dominance of students over each vocabulary item or the effectiveness of word formation in the student's mental lexicon. Lexical depth deals with the aspects that are connected to the improvement of literacy skills. According to Schmitt (2000), the depth of vocabulary refers to syntactic attributes, semantic representation, possible collocations, and pragmatic rules of the words or concepts. Studies have indicated the intricacy and multidimensionality of lexical knowledge have approached the construct of depth in a number of different ways (Read, 2004). Although this aspect of lexical knowledge has not received adequate attention, it is significant, particularly for those who are thinking in two languages simultaneously.

On the contrary, vocabulary breadth refers to the quantity of the words or the surface-level knowledge of many words that learners have at their disposal to use both productively and receptively (Read, 2000). This aspect of lexical knowledge has been defined as an individual's vocabulary size, or the approximate number of lexical items that a person knows (Nassaji, 2004; Qian, 2002; Zareva, 2005).

It can be observed that vocabulary depth and breadth are considered to be two different terms; however, they share a close empirical and conceptual relationship. Qian $(1999,2002)$ stated that the correlation between the vocabulary breadth and depth of L2 university students were .82 and 0.70 accordingly. In another study, Vermeer (2001) found a correlation of .85 for the depth and breadth of vocabulary among Dutch monolingual students at the kindergarten level and a correlation of .76 among their bilingual classmates; thus, she discussed that a significant difference between vocabulary depth and breadth could not be observed. Nurweni and Read (1999) stated that vocabulary breadth and depth might be connected if the students are at advanced proficiency levels, while the difference can be observed at lower proficiency levels. Such high correlations between these two dimensions of lexical knowledge show that vocabulary breadth and depth facilitate one another (Li \& Kirby, 2015). Li and Kirby (2015) also stated that at the beginning of language development, few words could be learned on the basis of their basic meanings. Nevertheless, with increases in the experience level of the learners, the learned words can be explained in more detail and associated with the vocabulary in various contexts, which contributes to the learning of new words (Haastrup \& Henriksen, 2000; Ma, 2009; Perfetti, 2007).

\section{M-Learning in Education}

Krashen (1989) predicted that a set of instructional aids aimed at language acquisition would motivate acquisition at the fastest possible rate. This language acquisition device would be verypowerful and effective in the future due to the progress and enhancements of second language learning and acquisition tools. In this regard, the 'chalk and talk' classroom, printed books, and methods used traditionally can be compared with the 
current strategies in language acquisition through the optimal use of technology (Govindasamy, Yunus, \& Hashim, 2019).

Implementing mobile technology in teaching and learning processes affected the paradigms of time, place, and the ways in which the school would be delivering the instruction. Such an aspect of technology would increase the considerations towards learning materials; it can improve learning and raise learners' motivation for a lifetime (Kristoffersen \& Ljungberg, 1998). Mobile learning is considered one of the extended versions of e-learning. One of the practical advantages of $\mathrm{m}$-learning is that it is accessible for students free from time and place restrictions. M-learning acts as a facilitator that supports the performance of students in learning environments. The flexibility of m-learning as it provides education for students who are in the process of learning at their own speed can be considered as another advantage. M-learning provides two-way communication to include the shy students who are unwilling to communicate more in the classes as well as the students who can share ideas with the teachers and peers easily. Teachers can use m-learning to send instructions to a large group of students in any academic context. Finally, m-learning is self-disciplined and self-motivated, which supports learning outside of time limitations and place restrictions (Alalawan, Alzahrani, \& Sarrab, 2013).

M-learning provides a distinct opportunity for both learners and teachers. The teachers greatly shorten the effort and time needed for organizing and repeating the lessons, while learners are able to repeat the lessons at any time and as often as they want. It should be mentioned that e-learning can take place inside and outside the classrooms, and especially that m-learning is popular among younger learners who grew up using mobile devices and who could be eager to keep learning outside the borders of a traditional classroom.

\section{M-learning and Vocabulary Learning}

There are several language-related experiments in m-learning literature that have integrated the recent innovations of mobile phone technologies into their pedagogical practices (e.g., Comas-Quinn, Mardomingo, \& Valentine, 2009; Hayati et al., 2013; Klimova, 2020; Mahdi, 2018; Nah, White, \& Sussex, 2008; Stockwell, 2007; Todd \& Tepsuriwong, 2008; Wang, 2017). The learning of vocabulary can be facilitated by technology in general and mobile devices in particular.

Govindasamy et al. (2019) made an attempt to examine the effectiveness of mobile phones to find the meaning of vocabulary in comparison to the conventional way of using a printed dictionary. To collect the required data, vocabulary pre- and post-tests were performed. The results revealed that mobile phones improved learners' knowledge in deeper vocabulary learning and vocabulary meaning compared to the printed dictionary.

Wang and Shih (2015) implemented some of the applications of vocabulary learning in their study with 93 Mandarin-speaking students in northern Taiwan and found that the results from the experimental group were remarkably better than from the control one, which employed the usage of traditional printed materials. WhatsApp, as an example of a functional application, gives users the ability to communicate and exchange texts freely, carry on individual conversations, and make calls. This famous application is accessible on all mobile platforms, such as Android, IOS, Symbian, Windows Mobile, etc.

In another research, Wu (2015) produced Word Learning-CET6, a mobile application, for teaching vocabulary to Chinese EFL learners. The experimental group received instruction using the application, while the control group was instructed to study and learn the lexicon themselves. The post-test scores showed a significant result between the two groups in favor of the experimental group.

\section{Texting in Education}

One of the extensively used characteristics of mobile phones that was initially under consideration in various research studies was the Short Message Service. SMSs as a communication tool transfer short text messages up to 160 characters by means of the Global System for Mobile Communication (GSM) enabled on mobile phones. This form of text messaging is one of the famous communication instruments, with 2.4 billion users around the world ${ }^{1}$. Many young people exchange SMSs with friends, with an average message length of 71 characters

1 Short Message Service. (2008). http://en.wikipedia.org/wiki/Short_message_service. 
(Grinter \& Eldridge, 2003). The term SMS illustrates both the messages and the medium (Kasesniemi \& Rautianen, 2002).

The process of teaching has changed over the years. The engagement of the learners in their learning process has increased, and essential opportunities have been given to them to explore the solutions. The usage of texting helps learners build foundational reading skills like phonological awareness and word recognition. Tomita (2009) states that text messaging motivates learners to write more and gives them additional communication opportunities. Some adversaries believe that texting can be motivational for those learners with low-level writing abilities; however, research reports have indicated that learners have the ability to distinguish between formal and informal writing.

In addition, text messaging provides learners with the ability to participate in silent communication (Katz \& Aakhus, 2002). In this type of communication, there is no need for the third party to know what any two other interlocutors are discussing, except when content is intentionally made known to a third party. Opinions are negotiated by text interlocutors without much interference or noise. As a consequence, learners naturally find it more comfortable to use text messages, specifically if they find themselves in conditions that are not able to make a call (North, Johnston, \& Ophoff, 2014). Therefore, learners use text messaging conveniently because it is quick, cheap, and affordable for transferring information (Mahmoud, 2013).

Many research studies have made a comparison between SMS-based vocabulary teaching and traditional methods of instructions. For instance, Zhang et al. (2011) and Lu (2008) tried to find the comparative effects of SMSs and printed materials. The findings of their research reports revealed that the group that received the SMSs performed better than the control group, in which the participants received printed materials, during the post-test. By the same token, Suwantarathip and Orawiwatnakul (2015) carried out a study to compare the effectiveness of teaching and practicing new words inside of the class via drills through SMSs for six weeks. The findings showed a positive and significant performance among the learners in the experimental group in comparison to their counterparts.

Hayati et al. (2013) examined the effects of teaching idioms to Iranian EFL learners. Participants were divided into three groups that were receiving various types of instruction. One of the groups, the self-stuy one, received the idioms along with the definitions and examples via printed materials. In the second group, the experimental one, the idioms were sent through SMSs, including four idioms, along with their meanings and sample examples. Finally, the last group, the control one, received short texts rather than sentence examples and the definitions. The findings revealed that all three groups had remarkably different scores. The group that received the SMSs achieved the highest marks, and those with self-study instruction received the lowest marks. Moreover, learners stated that mobile phones and SMSs were effective and desirable teaching tools.

In some research studies, the researchers compared the use of SMS with traditional approaches for teaching vocabulary to see which was better for learners. Tabatabaei and Goojani (2012) carried out a mobile phonebased study to investigate the effects of SMS on L2 English vocabulary acquisition. The participants wrote sentences between five and six words, which were sent through SMSs to their teacher and fellow students. The results showed that the experimental group which received SMSs significantly outperformed the control group on a vocabulary post-test. Both learners and their teachers indicated positive attitudes towards using SMSs for vocabulary learning.

Although a great number of studies showed that using SMSs and other applications on mobile phones are effective for vocabulary learning, the feasibility of such devices is limited. For example, SMSs can be pricey (Çavuş \& Ibrahim, 2009), or computer applications need to be adjusted for mobile phones, which may negatively affect their quality (Thornton \& Houser, 2005). Fortunately, mobile phone applications, which are popular and effective, can considerably facilitate mobile-learning activities. In addition, mobile-learning applications are beneficial to language instruction (Godwin-Jones, 2011).

Regarding the issues mentioned above, educators and researchers have attempted to incorporate texting into language teaching and self-regulated learning treatments to help L2 learners develop various skills (Cavus \& Ibrahim, 2009; Hayati, Jalilifar, \& Mashhadi, 2013; Kennedy \& Levy, 2008). Few research studies have examined the educational usage of mobile devices in learning vocabulary deeply (Browne \& Culligan, 2008; Kennedy \& 
Levy, 2008; Lu, 2008; Saran et al., 2012, Stockwell, 2008, 2010; Thornton \& Houser, 2005; Wong \& Looi, 2010; Zhang et al., 2011). Considering Qian's (2002) classification of lexical knowledge, the current study will focus on two out of the four dimensions, i.e., the breadth and depth of Iranian EFL learners' vocabulary items acquired with the use of text messaging. This study is part of a larger project of the researchers, following the line of two previous studies. In the first study, we investigated the reflection of vocabulary implementation through educational text messaging on EFL learners' reading skills. The results of the study revealed no meaningful discrepancy between the experimental and control groups based on their reading scores (Behforouz \& Frumuselu, 2021). In the second study, the efficiency of text messaging as an EFL instructional tool for learner autonomy and their perception toward the use of mobile-assisted language learning was investigated. The findings revealed that there were significant differences between the experimental and control groups' mean learner autonomy scores and learners showed positive views towards MALL and technology-based language learning (Behforouz \& Frumuselu, 2020). Considering the unavoidable relationship between lexical knowledge and reading comprehension discussed in many studies (Al-Khasawneh, 2019; Jamalipour \&Farahani, 2015; Kamal, 2019; Karakoç \& Köse, 2017; Rydland, et al., 2012; Zhang \& Annual, 2008), this study aims to analyze the effect of text messaging on EFL learners' vocabulary depth and breadth. Few studies could be found in the literature that applied SMS text messaging to pre-teaching vocabulary to EFL learners in Iran. There is a gap in the literature and the current study is expected to fill it.

It should be mentioned that the participants of the current study had no connection, a poor connection, or sometimes lacked a connection to the internet. This made it difficult for the students to receive the vocabulary items on a regular basis, which may have led to significant negative effects on the results. Still, they had access to their mobile phones, and sending the vocabulary by SMS was manageable for the researchers and an appropriate channel of communication for the students. Therefore, the researcher decided to use SMS text messaging to implement the vocabulary items as the treatment.

The current paper aims at answering the following questions:

RQ1: Does text messaging have a statistically significant impact on Iranian EFL learners' vocabulary depth? RQ2: Does text messaging have a statistically remarkable impact on Iranian EFL learners' vocabulary breadth?

\section{Materials and Methods}

This section presents the method used to design the study and how data collection was undertaken. The study aimed to investigate if text messaging had any statistical significance on Iranian EFL learners' vocabulary depth and breadth. To this end, the comprehensive procedure including sampling, instrumentation, data collection, and data analysis is explained in detail.

\section{Participants}

A total of 37 learners within the age range of 21 to 26 years old were the final participants of the study. They were university students with different majors (Chemistry, Computer Science, Civil Engineering, and Electrical Engineering) studying general English at the Islamic Azad University-South Tehran Branch. To measure the homogeneity of the sample population on the basis of their English proficiency level, the first step was the administration of the Oxford Placement Test (OPT). Consideringthe OPT scale, those participants who scored from 28 to 36 were selected as the research sample of the present study. Based on the OPT scale, scores from 28-36 are regarded to be at the pre-intermediate level of language proficiency.They were Persian native speakers and all of them had a mobile phone to use for the study. It should be mentioned that the students were taking a reading comprehension course in the same semester as part of their regular English curriculum.

\section{Design of the Study}

This study is an experiment with a one-group pre-test post-test design. It is worth mentioning that learners received 108 vocabulary items through SMS text messages three times a week for six weeks. Thus, they received six vocabulary items per session. 


\section{Instruments}

\section{Oxford Placement Test}

In order to gather sufficient information, the following tools were used, respectively. An OPT was administered to measure participants' ability to communicate in English. This test was used in this study since it is easy to administer based on produced doctorate theses and articles in Iran, and it is well-known among academics. The OPT is a quick way of assessing the approximate level of learners' knowledge of English grammar and usage. The allocated time to complete the test was 55 minutes. This test consists of two parts with 60 multiplechoice items and cloze tests. The first part consists of 40 questions, and the second part includes 20 questions. Participants were instructed to read the items and then choose the correct answers among the choices. The incorrect answers did not result in negative points. Based on the norms of the test, the participants` scores were ranked from beginner to advanced levels. Table 1 shows the OPT scale.

\section{Table 1}

Oxford Placement Test Scale

\begin{tabular}{cccccc}
\hline Beginners & Elementary & Lower-Intermediate & Upper-Intermediate & Advanced & Very Advanced \\
\hline $1-17$ & $18-27$ & $28-36$ & $37-47$ & $48-55$ & $56-60$ \\
\hline
\end{tabular}

\section{Word Associate Test (WAT)}

The second instrument used for this study was a word associate test (WAT), which is a well-known method of measuring learners' vocabulary depth. The WAT was devised by Read $(1993,1998)$ to estimate L2 learners' depth of lexical knowledge on the basis of three relationships among mental lexicon words: paradigmatic (meaning), syntagmatic (collocation), and polysemy. It includes 40 items, including one stimulus word (an adjective) and two boxes, one box contains four adjectives that are either synonyms or polysemous with the stimulus word, andthe other contains nouns that can collocate with the stimulus word. There are always four correct options for each item. Read (1993) reported the reliability of the test as 0.93; later, Qian $(1999,2002)$ and Nassaji (2004) estimated above 0.90 . To score the WAT, one point is awarded for the correct match of each word; therefore, 160 is the highest score. Figure 1 is an excerpt from this test.

\section{Figure 1}

A Sample Item from the WAT (Read, 1998)

\begin{tabular}{l|l}
\hline $\begin{array}{l}\text { Sudden } \\
\square \text { beautiful } \square \text { quick } \square \text { surprising } \square \text { thirsty }\end{array}$ & ■ change $\square$ doctor $\square$ noise $\square$ school \\
\hline
\end{tabular}

\section{The Updated Vocabulary Level Test (UVLT)}

The updated vocabulary level test (UVLT) was the third instrument of this study to assess the learners' vocabulary size/breadth. The UVLT is probably the commonly used instrument to assess L2 learners' lexical knowledge (Read, 2000). It was initially created by Nation (1983) and later modified by Schmitt, Schmitt, and Clapham (2001) to identify how well learners know useful English words and the extent to which learners could distinguish the form-meaning relations of words at four levels of word frequency $(2000,3000,5000,10000)$ and an academic vocabulary level. These four levels of frequency are based on the General Service List (GSL) (West, 1953), Kučera and Francis (1967), and Thorndike and Lorge's (1944) list, while the other section (academic) is based onXue and Nation's (1984) University Word List.

The researchers of the present study used the UVLT developed and validated by Webb, Sasao, and Balance (2017) at five levels of word frequency $(1000,2000,3000,4000$, and 5000). It is worth noting that this test has the potential to measure all the levels together or measure the levels individually. There are 10 clusters with six words, including distractors and keys along with three definitions in each level. Participants are asked to put a checkmark $(\square)$ under the word corresponding with each meaning.

Unlike multiple-choice tests, the UVLT decreases the percentage of guessing the answer because the test shows the same type of vocabulary, so there are not any syntactic clues for the correct responses. The test-takers 
should match three words to their definitions. To score the UVLT, a correct check earns one point for each word; therefore, the highest score is 150 points. Regarding the abovementioned information, the test used in the present study was the modified for use as a vocabulary size test or a breadth of lexical knowledge test. Figure 2 shows a sample item from the UVLT.

Figure 2

An Example from the UVLT (Webb, Sasao, \& Balance, 2017)

\begin{tabular}{|c|c|c|c|c|c|c|}
\hline & game & island & mouth & movie & song & yard \\
\hline land with water all around it & & $\sqrt{ }$ & & & & \\
\hline part of your body used for eating and talking & & & $\sqrt{ }$ & & & \\
\hline piece of music & & & & & $\sqrt{ }$ & \\
\hline
\end{tabular}

\section{Procedure}

This study was conducted during the reading module of the fall semester in the 2019-2020 academic year, over a period of an 18-session treatment lasting six consecutive weeks. The participants received SMSs three times a week with vocabulary items related to the content of their coursebook. 108 relevant vocabulary items were selected and they received six vocabulary items via SMS every session. The researchers used text messaging through m-learning to improve their students' vocabulary depth and breadth.

To collect data for the present study, the researcher went through the following procedure: After the administration of an Oxford Placement Test (OPT), 37 undergraduate Iranian EFL learners aging from 21 to 26 studying at the Islamic Azad University-South Tehran Branch were selected as the sample of the current study. Since this study is a part of a larger study, the initial population consisted of 88 participants. Based on their scores on the OPT scale, the participants were placed in the pre-intermediate level.

The second step was devoted to the administration of the UVLT and the WAT to assess the learners' breadth and depth of lexical knowledge. Both tests were administered during one session. Based on Schmitt et al. (2001), the allocated time of the UVLT was 31 minutes; as Qian $(1999,2002)$ and Nassaji (2004) stated, the time for completing the WAT was 30 minutes. However, in this study, the time allocated for completing both tests (UVLT \& WAT) was 70 minutes. The participants were told to select the option that best described the meaning of the stem word in the absence of some context, and they were supposed to select the option that matched the meaning of the stem word and do this for all the items. It was mentioned that their selection should not be random, and they should choose precisely. There were no negative points for incorrect answers. The UVLT and WAT tests were administered to all the participants before the beginning of the treatment.

After administrating the WAT and UVLT as pre-tests, the treatment procedure began.A list of vocabulary words from their coursebook and also the number of words from the updated vocabulary level test appropriate for pre-intermediate learners were selected and delivered to them via SMS, six items in an SMS three times a week. They received SMSs containing vocabulary items for 18 sessions over six consecutive weeks. Each word was used in one short sentence, with a synonym and a single-word Persian translation at the end of the sentence in parentheses. The SMSs were delivered to a group of 37 learners at once.

At the end of the experiment, the WAT and the UVLT tests were given as post-tests to see the effect of text messaging on the depth and breadth of their lexical knowledge, and the scores of pre-test and post-test were compared employing the nonparametric Wilcoxon signed-rank tests.

\section{Data Analysis and Findings}

In this section, the analysis and the interpretation of data collected over a period of six weeks at the Islamic Azad University-South Tehran Branch are presented. After collecting the required data from the research instruments, descriptive analysis, focusing on the basic features of the data, and inferential analysis, the researched attempted to reach conclusions that extended beyond the immediate data. 
To have a homogenized population based on the English proficiency level, the OPT was conducted. 37 students received similar OPT scores, ranging from 28 to 36 (pre-intermediate level). Table 2 shows the descriptive statistics of the homogenized participants in which the mean and the standard deviation of the homogenized participants were 31.66 and 2.22, respectively. The standard deviation means that most of the scores are close to the average; therefore, the participants' scores show that they had a homogenous general English proficiency level. Since the participants of this study were participating in another study, 74 of them were selected primarily, but later on, for the purpose of the current study, 37 pre-intermediate students were selected as the sample.

\section{Table 2}

The Descriptive Statistics of the Oxford Placement Test

\begin{tabular}{llcccc}
\hline & N & Minimum & Maximum & Mean & Std. Deviation \\
\hline OPT Homogenized & 37 & 28.00 & 36.00 & 31.35 & 2.54 \\
Valid N (listwise) & 37 & & & & \\
\hline
\end{tabular}

The first research question investigated whether text messaging via m-learning could have any statistically significant effect on the learners' vocabulary depth. Before testing this research hypothesis, it was necessary to check whether the data were normally distributed. Therefore, a One-Sample Shapiro-Wilk test was run. Table 3 below displays the results of the One-Sample Shapiro-Wilk test.

\section{Table 3}

One-Sample Shapiro-Wilk Test of Normality

\begin{tabular}{lccc}
\hline & \multicolumn{3}{c}{ Shapiro-Wilk } \\
\cline { 2 - 4 } & Statistic & df & Sig. \\
\hline Depth_Pre & .900 & 37 & .003 \\
Depth_Post & .903 & 37 & .004 \\
\hline
\end{tabular}

As indicated in Table 3, the normality of data distribution was not confirmed $(\mathrm{P}<.05)$. It means that the data were not normally distributed; therefore, a nonparametric test should be used. As a result, the nonparametric Wilcoxon signed-rank test was used for mean comparison. Table 4 shows the result.

Table 4

Analysis of the Pre-test/Post-test based on Depth Scores

\begin{tabular}{lccccc}
\hline & N & Min & Max & Mean & SD \\
\hline Depth_Pre & 37 & 64.00 & 87.00 & 73.189 & 7.615 \\
Depth_Post & 37 & 64.00 & 88.00 & 73.243 & 7.646 \\
Valid N (listwise) & 37 & & & & \\
\hline
\end{tabular}

Table 4 reveals that mean of the post-test was higher than the mean score of the pre-test $($ Mpost $=73.24>$ Mpre= 73.18).Table 5 below reveals the analysis of the Wilcoxon signed-rank test.

\section{Table 5}

Analysis of Wilcoxon Signed-Rank Test Based on the Depth Scores

\begin{tabular}{lc}
\hline & Depth_Post - Depth_Pre \\
\hline $\mathrm{Z}$ & $-1.000^{\mathrm{b}}$ \\
Asymp. Sig. (2-tailed) & .317 \\
\hline
\end{tabular}


The Wilcoxon signed-rank test revealed no statistically meaningful discrepancy between the pre-test and posttest of the depth scores $(Z=-1, p=0.317)$. Thus, text messaging via m-learning did not have any statistically significant effect on learners' vocabulary depth.

The second question of this study sought to investigate whether text messaging via m-learning could have any statistically significant effect on learners' vocabulary breadth. Before testing this research hypothesis, it was necessary to check whether there was a normality of the data distribution for the pre-/post-test scores. To do this, the researchers conducted a One-Sample Shapiro-Wilk test. Table 6 below displays the results.

\section{Table 6}

One-Sample Shapiro-Wilk Test of Normality

\begin{tabular}{lccc}
\hline & \multicolumn{3}{c}{ Shapiro-Wilk } \\
\cline { 2 - 4 } & Statistic & df & Sig. \\
\cline { 2 - 4 } Breadth_Pre & .940 & 37 & .048 \\
Breadth_Post & .875 & 37 & .001 \\
\hline
\end{tabular}

As indicated in Table 6, the normality of data distribution was not confirmed $(\mathrm{P}<.05)$. It means that the sample data was not drawn from a normally distributed population. Therefore, the nonparametric Wilcoxon signed-rank test was used for mean comparison. Table 7 below shows the results.

\section{Table 7}

Analysis of the Pre-test/Post-test of the Breadth Scores

\begin{tabular}{lccccc}
\hline & N & Min & Max & Mean & SD \\
\hline Breadth_Pre & 37 & 66.00 & 84.00 & 74.135 & 5.266 \\
Breadth_Post & 37 & 69.00 & 92.00 & 76.108 & 6.393 \\
Valid N (listwise) & 37 & & & & \\
\hline
\end{tabular}

According to Table 7 above, the mean score of the post-test was higher than the mean score of the pre-test (Mpost $=76.10>$ Mpre= 74.13). To analyze further, a Wilcoxon signed-rank test was conducted.

\section{Table 8}

Analysis of the Wilcoxon Signed-Rank Test Based on the Breadth Scores

\begin{tabular}{ll}
\hline & Breadth_Post - Breadth_Pre \\
\hline $\mathrm{Z}$ & $-5.005^{\mathrm{b}}$ \\
Asymp. Sig. (2-tailed) & .000 \\
\hline
\end{tabular}

The test showed a statistically meaningful difference between the pre-test and post-test on the learners vocabulary breadth scores $(Z=-5, p<.05)$. Therefore, the results enabled the researchers to claim that text messaging via m-learning had a statistically significant effect on the learners' vocabulary breadth. This means that the use of text messaging increased the learners' vocabulary size.

\section{Discussion}

Since the process of learning vocabulary is one of the substantial features of language teaching, the present study addressed Iranian EFL learners' breadth and depth of lexical knowledge via the use of m-learning text messages.

The findings of this study revealed the effects of text messaging via m-learning on EFL learners' lexical knowledge in general, and breadth in particular. Based on the results related to the first research question, no 
significant differences were found between the learners' pre-test and post-test scores on the WAT. This may lead to the conclusion that text messaging via m-learning did not improve learners' depth of lexical knowledge. The Iranian EFL learners' lack of improvement in vocabulary depth may have several causes, which will be discussed below. Remembering vocabulary items sent via SMS may be possible for a short period of time, but the effects may not be long lasting, so the post-test employed after the six-week treatment did not reveal encouraging results in this sense. In contrast, if weekly tests were to be collected, better results and performance may be expected in a shorter term. Additionally, we believe that more practice exercises related to the vocabulary items in communicative situations should have been employed in order for the learners to acquire them more efficiently. In this sense, the SMS tool was used as a one-way form of communication, which is coming from the teacher side only. As there were no activities to foster teacher-student or student-student communication, the results did not reveal visible improvement in the learners' vocabulary quality of understanding. The words and the definitions that can be sent by SMSs are limited, and this might be problematic for students who have lower proficiency levels (beginner, elementary, and pre-intermediate levels) in the EFL context because they would need further support to develop their lexical knowledge.

As mentioned earlier, this study is a part of a larger one. The findings of the previous study carried out by Behforouz and Frumuselu (2021) showed that vocabulary learning via short messages did not affect Iranian EFL learners` ability to comprehend pre-intermediate-level texts. This is in line with the studies carried out by Li and Kirby (2014) and Rahman, Iqbh, and Zanal (2019), which stated that vocabulary depth can contribute to and predict reading comprehension improvement.

Thus, the findings of this study based on the results of vocabulary depth are consistent with Alemi et al. (2012), who examined the impact of texting on Iranian learners' vocabulary detainment and learning. They found nosignificant difference between the groups on the pre- and post-tests. However, the results are not in line with the findings of several research studies (Lu, 2008; Saran \& Seferoglu, 2010; Zhang et al., 2011) in which the experimental groups received the materials by MMS or SMS, while the control group continued with a traditional style of material delivery and they reported substantial benefits and gains in terms of vocabulary acquisition. Therefore, further investigation is needed in order to elaborate on this aspect and find the appropriate methodology and types of materials to foster interactions and enhance learners' vocabulary deep learning. Analyzing this tool in a different context with different types of students coming from other backgrounds could lead to contrasting findings, so employing a variety of methods and analyzing learners' reactions and vocabulary acquisition should be vital for using SMSs as an educational tool effectively.

The second research question sought to investigate whether text messaging via m-learning had any statistically significant effect on the learners' vocabulary breadth. The results of the Wilcoxon signed-rank test for the breadth scores show a statistically meaningful discrepancy between the breadth scores on the pre- and posttests. It means that the learners' vocabulary size improved significantly after the treatment. Indeed, using SMS as an educational tool has hadapositiveimpactonthe learners' lexicalknowledge.The difference suggests that there was an improvement in the performance of the participants in terms of their vocabulary breadth before and after the treatment. Although there are different perspectives on the proper threshold level, Sutarsyah, Nation, and Kennedy (1994) suggested a level of 4,000-5,000 word families, while Coady et al. (1993) proposed an explicit understanding of the words at the level of 3,000 word families. The current results are encouraging and show positive effects in this sense.

The findings related to the second research question based on vocabulary size are in line with many previous research studies. Motallebzadeh and Ganjali (2011) conducted a study in a university context in which the experimental group received some vocabulary through short messages, while the control group received paperbased instruction. The results of the study revealed that the participants of the experimental group showed better performance on the vocabulary test. Some other research studies were conducted by Başoğlu and Akdemir (2010), Liu and Chen (2014), Lu (2008), Rahimi and Miri (2014), Saran et al. (2012), Wu (2015), and Zhang et al. (2011) that are in line with the findings of this study. They investigated the role of mobile applications, SMS, and mobile systems in vocabulary learning, and the performance of the experimental groups showed that participants who received vocabulary through electronic platforms outperformed those who received the instructions on paper. Basoglu and Akdemir (2010) also showed that using mobile phones to teach vocabulary can have more positive impact on the learners than teaching them using flashcards. In another study, Suwantarathip and Orawiwatnakul (2015) stated that students in the experimental group receiving 
mobile-assisted vocabulary activities performed better than the students of the control group who received paper-based exercises. Saricoban and Ozturan (2013) conducted a study to measure the effect of mobile phone on teaching technical words and sentences. The findings of the study showed that those students who received the treatment by means of mobile phones were motivated and learned the vocabulary efficiently. Thus, the findings of our study are in line with the aforementioned studies and using SMSs as an educational tool in the EFL context could lead to vocabulary size improvement and foster their acquisition over the long term. It should also be mentioned that the positive results could be explained in terms of learners' motivation and openness to experience learning outside the so-called 'traditional' environment and receiving vocabulary items in context via their mobile phones helped them gain knowledge after the six-week treatment. However, additional investigations should be carried out in order to reach definitive conclusions with learners coming from different backgrounds and proficiency levels, as this could have influenced the results of the current study.

Although this study achieved its aims, there were some unavoidable limitations. First, because of the small size of the sample, the results might not be generalizable to other types of populations. Second, the post-tests were administered immediately after finishing the treatment. A further study can be carried out with delayed posttests to check learners' vocabulary retention. Third, the focus of the present study is vocabulary depth and breadth; therefore, more research studies should be carried out on the interaction of breadth and depth of lexical knowledge and reading performance. Fourth, only pre-intermediate level learners took part in this study, so another study could be carried out with language learners of other proficiency levels in order to corroborate the current results. Fifth, the focus of the study was limited to sending SMS text messages to improve learners' lexical knowledge; so additional goals could be added in order to have a more in-depth view of the learners' tendencies when they are in contact with this type of educational tool. Sixth, in this study, text messaging via $\mathrm{m}$-learning was the medium of instruction, so other studies could be carried out with different $\mathrm{m}$-learning applications. Additionally, more qualitative analyses are required in these types of studies in order to grasp not only the learners' performance but also their response to the implementation of text messaging as an educational medium in the EFL classrooms.

In general, the use of text messaging through mobile phones has been used successfully in a variety of ways in the learning language process, as stated in the results of the current paper. As a result, policymakers and school administrators should consider text messaging via m-learning as another educational instrument that has many latent benefits for foreign language learning.

\section{Conclusion}

Considering the rapid improvement of technology, mobile devices can be considered motivational learning tools. Teachers and learners are tired of the old-fashioned methods of vocabulary learning, like memorization and repetition. Using various kinds of applications facilitates learning and it also generates variation and excitement. The current study was undertaken to measure the usefullness of mobile phone text messaging when introducing vocabulary items to EFL university learners in Iran. The basic assumptions were that text messaging through m-learning improves learners' breadth and depth of lexical knowledge. The findings of the present study indicated that using text messaging via m-learning was effective for learners' vocabulary breadth, and there was a meaningful difference between the post-test scores of the study group in terms of vocabulary breadth. The data concerning vocabulary depth showed a slight but not statistically remarkable discrepancy at the end of the study. The findings of this study showed the treatment process used in this study affected learners' breadth of lexical knowledge rather than their depth. The findings also showed that vocabulary learning through SMS text messaging has a positive effect on learners' lexical knowledge in general and the size of their vocabulary in particular.

The results of this study can have instructional implications for teachers and learners and help them use mobile learning more appropriately for effective vocabulary learning. Designing and planning these type ofvocabulary activities should be considered by educators and teachers in order to foster learners' lexical knowledge.Learners' awareness of the depth of lexical knowledge can be raised by teachers in a variety of ways. Activities and tasks proposed by Schmitt and Schmitt's (1995), such asvocabulary notebooks could be useful in this case. Learners can improve their lexical knowledge using mobile learning at any point in time. In conclusion, the use of mobile phones as a pedagogical instrument will surely improve the process of learning and teaching. 
Despite the encouraging findings of the current study that text messaging positively affects L2 lexical learning, some limitations were found. With a small sample of pre-intermediate English students at one university, the results of this study may not be completely generalized. The treatment process lasted only six weeks. A longer time allocated for the treatment might have resulted in different findings. Observing individual learners would be meaningful for finding how and when they checked the text messages for vocabulary learning on their mobile phones.

\section{Conflicts of interest}

The authors declare that they have no conflicts of interest.

\section{References}

Ağca, R. K., \& Özdemir, S. (2013). Foreign language vocabulary learning with mobile technologies. ProcediaSocial and Behavioral Sciences, 83, 781-785. https//doi.org/10.1016/j.sbspro.2013.06.147

Agdam, S. J., \& Sadeghi, K. (2014). Two formats of word association tasks: A study of depth of word knowledge. English Language Teaching, 7(10), 1-12. http://dx.doi.org/10.5539/elt.v7n10p1

Alalwan, N., Alzahrani, A., Sarrab, M. (2013). M-learning the next generation of education in cyberspace. World Academic of Science, Engineering and Technology, 74, 642-645.

Alemi, M., Sarab, M., \& Lari, Z. (2012). Successful learning of academic word list via MALL: Mobile Assisted Language Learning. International Education Studies, 5(6), 99-109. https//doi.org/:10.5539/ies. v5n6p99

Alexander, B. (2004). Going nomadic: Mobile learning in higher education. EDUCAUSE Review, 35(5), 29-35.

Al-Khasawneh, F. (2019). The impact of vocabulary knowledge on the reading comprehension of Saudi EFL learners. Journal of Language and Education, 5(3), 24-34. doi: https://doi.org/10.17323/jle.2019.8822

Alzu'bi M. A. M., \& Sabha, M. R. N. (2013). Using mobile-based email for English foreign language learners. Turkish Online Journal of Educational Technology, 12(1), 178- 186.

Anderson, R.C., \& Freebody, P. (1981). Vocabulary knowledge. In J. T.Guthrie (Ed.), Comprehension and teaching: Research reviews (pp.77-117). International Reading Association.

Aviad, T. L., \& Laufer, B. (2013). Lexical properties in the writing of foreign language learners over eight years of study: single words and collocations. In C. Bardel, C. Lindquist, \& L. Laufer (Eds.), L2 vocabulary acquisition, knowledge and use new perspectives on assessment and corpus analysis (pp. 127-148). European Second Language Association.

Başoğlu, E., \& Akdemir, O. (2010). A comparison of undergraduate students' English vocabulary learning: Using mobile phones and flashcards. Turkish Online Journal of Educational Technology, 9(3), 1-7.

Behforouz, B. \& Frumuselu, D. A. (2020). The impact of text messaging as an instructional tool to enhance learner autonomy and perception. International Journal of Learning, Teaching and Educational Research, 19(11), 184202. https://doi.org/10.26803/ijlter.19.11.11

Behforouz, B. \& Frumuselu, D. A. (2121). The reflection of vocabulary implementation through educational texting on EFL learner's reading skill. International Journal of Interactive Mobile Technologies, 15(1), 88-103.

Brann, A., Gray, T., Zorfass, J., \& Power (2009). Using multimedia to support reading instruction. http://www. ldonline.org/article/61326/.

Browne, C., \& Culligan, B. (2008). Combining technology and IRT testing to build student knowledge of highfrequency vocabulary. The JALT CALL Journal, 4(2), 3-16. https://doi.org/10.29140/jaltcall.v4n2.59

Cavus, N., \& Ibrahim, D. (2009). M-Learning: An experiment in using SMS to support learning new English language words. British Journal of Educational Technology, 40(1), 78-91. https://doi.org/10.1111/j.14678535.2007.00801.x

Chapelle, C.A. (1998). Construct definition and validity inquiry in SLA research. In L. F. Bachman, \& A. D. Cohen (Eds.), Interfaces between second language acquisition and language testing research (pp. 32-70). Cambridge University Press.

Chen, C. M., \& Chung, C. J. (2008). Personalized mobile English vocabulary learning system based on item response theory and learning memory cycle. Computers \& Education, 51(2), 624-645. https//doi.org/10.1016/j. compedu.2007.06.011

Chen, N. S., Hsieh, S. W., \& Kinshuk (2008). Effects of short-term memory and content representation type on mobile language learning. Language Learning \& Technology, 12(3), 93-113. 
Coady, J., Magotto, J., Hubbard, P., Graney, J., \& Mokhtari, K. (1993). High frequency vocabulary and reading proficiency in ESL readers. In T. Huckin, M. Haynes, \& J. Coady (Eds.), Second language reading and vocabulary learning (pp. 217- 228). Ablex.

Comas-Quinn, A., Mardomingo, R., \& Valentine, C. (2009). Mobile blogs in language learning: making the most of informal and situated learning opportunities. ReCALL, 21(1), 96-112. https://doi.org/10.1017/ S0958344009000032

Dağdeler, K. O., Konca, M. Y., \& Demiröz, H. (2020). The effect of Mobile-Assisted Language Learning (MALL) on EFL learners' collocation learning. Journal of Language and Linguistic Studies, 16(1), 489-509.

Farangi, M. R., Kamyab, J., Izanlu, M., \& Ghodrat, N. (2017). The effect of using SMS as a post task activity on Iranian EFL learners' grammar knowledge. Journal of Language Teaching and Research, 8(2), 392-403. https:// doi.org/10.17507/JLTR.0802.24

Godwin-Jones, R. (2011). Mobile apps for language learning. Language Learning \& Technology, 15(2), 2-11.

Govindasamy, P., Yunus, M. M., \& Hashim, H. (2019). Mobile assisted vocabulary learning: Examining the effects on students' vocabulary enhancement. Universal Journal of Educational Research, 7(12A), 85-92. 10.13189/ ujer.2019.071911

Grinter, R., \& Eldridge, M. (2003). Wan2tlk? Everyday text messaging. In Proceedings of the SIGCHI conference on Human factors in computing systems (pp. 441-448). Association for Computing Machinery. https://doi. org/10.1145/642611.642688

Haastrup, K., \& Henriksen, B. (2000). Vocabulary acquisition: Acquiring depth of knowledge through network building. International Journal of Applied Linguistics, 10, 221- 40. https://doi.org/10.1111/j.1473-4192.2000. tb00149.x

Hayati, A., Jalilifar, A., \& Mashhadi, A. (2013). Using short message service (SMS) to teach English idioms to EFL students. British Journal of Educational Technology, 44(1), 66-81. https://doi.org/10.1111/j.14678535.2011.01260.x

Henriksen, B. (1999). Three dimensions of vocabulary development. Studies in Second Language Acquisition, 21(2), 303-317. https://doi.org/10.1017/S0272263199002089

$\mathrm{Hu}, \mathrm{Z}$. (2013). Vocabulary learning assisted by mobile phones: Perceptions of Chinese adult learners. Journal of Cambridge Studies, 8(1), 139-154. https//doi.org/10.17863/CAM.1468.

Jamalipour, S., \& Farahani, A. A. K. (2015). The effect of vocabulary knowledge and background knowledge on Iranian EFL learners' 12 reading comprehension. Journal of Applied Linguistics and Language Research, 2(2), 107-121.

Kamal, S. M. (2019). Developing EFL learners' vocabulary by reading English comprehension in EFL classroom. International Journal of English Language and Literature Studies, 8(1), 28-35.

Kasesniemi, E. L., \& Rautiainen, P. (2002). Mobile culture of children and teenagers in Finland. In Perpetual contact: Mobile communication, private talk, public performance (pp. 170-192). Cambridge University Press.

Katz, E., \& Aakhus, M. A. (Eds.). (2002). Perpetual contact: Mobile communication, private talk, public performance. Cambridge University Press.

Kaivanpanah, S., \& Zandi, H. (2009). The role of depth of vocabulary knowledge in reading comprehension in EFL contexts. Journal of Applied Sciences, 9(4), 698-706. https://dx.doi.org/10.3923/jas.2009.698.706

Karakoç, D., \& Köse, G. D. (2017). The impact of vocabulary knowledge on reading, writing and proficiency scores of EFL learners. Dil ve Dilbilimi Çalışmaları Dergisi, 13(1), 352-378.

Kennedy, C., \& Levy, M. (2008). L'italiano al telefonino: Using SMS to support beginners' language learning. ReCALL, 20(3), 315-330. https://doi.org/10.1017/S0958344008000530

Kieffer, M. J., \& Lesaux, N. K. (2012b). Knowledge of words, knowledge about words: Dimensions of vocabulary in first and second language learners in sixth grade. Reading and Writing, 25, 347-373. https://psycnet.apa. org/doi/10.1007/s11145-010-9272-9

Klimova, B. (2020). Mobile learning and its impact on learning English vocabulary. In J. Park., L. Yang., Y.S. Jeong, \& F. Hao. (Eds.), Advanced multimedia and ubiquitous engineering. MUE 2019, FutureTech 2019. Lecture Notes in Electrical Engineering (vol 590, p. 271-276). Springer. http://dx.doi.org/10.1007/978-981-32-9244-4_38

Krashen, S. D. (1989). Principles and practice in second language acquisition. Pergamon Press Inc.

Kristoffersen, S., \& Ljungberg, F. (1998). Representing modalities in mobile computing. Proceedings of Interactive Applications of Mobile Computing (pp. 643-648). Rosctock.

Kuc era, H., \& Francis, W. N. (1967). A computational analysis of presented by American English. Brown University Press.

Kukulska-Hulme, A. (2013). Re-skilling language learners for a mobile world. https://www.tirfonline.org/ publications/mobile-assisted-language-learning/re-skilling-language-learners-for-a-mobile-world/ 
Li, M., \& Kirby, R. J. (2015). The effects of vocabulary breadth and depth on English reading. Applied Linguistics, 36(5), 611-634. https://doi.org/10.1093/applin/amu007

Liaw, S. S., Hatala, M., \& Huang, H. M. (2010). Investigating acceptance of mobile learning to assist individual knowledge management: Based on activity theory approach. Computers \& Education, 54(2), 446-454. http:// dx.doi.org/10.1016/j.compedu.2009.08.029

Liu, Y., \& Chen, N. S. (2008). An adoption model for mobile learning. In S. Krishnamurthy (Ed.), Proceeding for the IADIS international Conference E-Commerce (pp. 251-256). IADIS.

Liu, P. L., \& Chen, C-J. (2014). Learning English through actions: A study of mobile-assisted language learning. Interactive Learning Environments, 23(2), 158-17. https//doi.org/10.1080/10494820.2014.959976

$\mathrm{Lu}$, M. (2008). Effectiveness of vocabulary learning via mobile phone. Journal of Computer Assisted Learning, 24(6), 515-525. https://doi.org/10.1111/j.1365-2729.2008.00289.x

$\mathrm{Ma}, \mathrm{Q}$. (2009). Second language vocabulary acquisition. Peter Lang.

Mahdi, H. S. (2018). Effectiveness of mobile devices on vocabulary learning: A meta-analysis. Journal of Educational Computing Research, 56(1), 134-154. https://doi.org/10.1177\%2F0735633117698826

Mahmoud, S. S. (2013). The effect of using English SMS on KAU foundation year students' speaking and writing performance. American International Journal of Social Science, 2(2), 13-22.

Meara, P. (1996). The vocabulary knowledge framework. Vocabulary Acquisition Research Group Virtual Library, 5(2), 1-11.

Mehrpour, S., \& Montasseri, Z. (2019). The effect of using the MoodleReader Module on Iranian EFL learners' vocabulary depth and breadth. Journal of Modern Research in English Language Studies, 6(2), 128-103.

Motallebzadeh, KH., Ganjali, R. (2011). SMS: Tool for L2 Vocabulary Retention and Reading Comprehension Ability. Journal of Language Teaching and Research, 2(5), 1111-1115. https://doi.org/10.4304/jltr.2.5.11111115

Nah, K. C., White, P., \& Sussex, R. (2008). The potential of using a mobile phone to access the Internet for learning EFL listening skills within a Korean context. ReCALL: the Journal of EUROCALL, 20(3), 331-437. https://doi.org/10.1017/S0958344008000633

Nassaji, H. (2004). The relationship between depth of vocabulary knowledge and L2 learners' lexical inferencing strategy use and success. Canadian Modern Language Review, 61(1), 107-134. http://dx.doi.org/10.3138/ cmlr.61.1.107

Nassaji, H. (2006). The relationship between depth of vocabulary knowledge and L2 learners' lexical inferencing strategy use and success. Modern Language Journal, 90(3), 387-401. https://doi.org/10.1111/j.15404781.2006.00431.x

Nation, I. S. P. (1983). Testing and teaching vocabulary. Guidelines, 5(1), 12-25.

Nation, I. S. P. (1990). Teaching and learning vocabulary. Newbury House.

North, D., Johnston, K., \& Ophoff, J. (2014). The use of mobile phones by South African university students. Issues in Informing Sscience and Information Technology, 11, 115-138.

Nurweni, A., \& Read, J. (1999). The English vocabulary knowledge of Indonesian university students. English for Specific Purposes, 18,161-75.

Pedersen, S., \& Liu, M. (2003). Teachers' beliefs about issues in the implementation of a student-centered learning environment. Educational Technology Research \& Development, 51(2), 57-76. https://doi.org/10.1007/ BF02504526

Perfetti, C. A. (2007). Reading ability: Lexical quality to comprehension. Scientific Studies of Reading, 11, 357-83.

Qian, D. D. (1999). Assessing the roles of depth and breadth of vocabulary knowledge in reading comprehension. Canadian Modern Language Review, 56(2), 282-307. https://doi.org/10.1080/10888430701530730

Qian, D. D. (2002). Investigating the relationship between vocabulary knowledge and academic reading comprehension: an assessment perspective. Language Learning, 52(3), 513- 536. https://doi.org/10.1111/14679922.00193

Qian, D. D. (2005). Demystifying lexical Inferencing: The role of aspects of vocabulary knowledge. TESL Canada Journal, 22(2), 34-54.

Qian, D.D., \& Schedl, M. (2004). Evaluation of an in-depth vocabulary knowledge measure for assessing reading comprehension. Language Testing, 21(1), 28-52. https://doi.org/10.1191\%2F0265532204lt273oa

Rahimi, M., \& Miri, S. S. (2014). The impact of mobile dictionary use on language learning. Procedia-Social and Behavioral Sciences, 98, 1469-1474. https//doi.org/ 10.1016/j.sbspro.2014.03.567

Rahman, Z. U., \& Iqbal, Z. (2019). Relationship of Breadth and Depth of Vocabulary Knowledge and Reading Comprehension in Learning English. Bulletin of Education and Research, 41(3), 89-100.

Read, J. (1989). Towards a deeper assessment of vocabulary knowledge. Paper presented at the 8th annual meeting 
of the International Association of Applied Linguistics (Sydney, August 16-21). (No. ED 301048). Eric Clearing House on Languages and Linguistics. .

Read, J. (1993). The development of a new measure of L2 vocabulary knowledge. Language Testing, 10(3), 355371. https://doi.org/10.1177\%2F026553229301000308

Read, J. (1998). Validating a test to measure depth of vocabulary knowledge. In A. J. Kunnan (Ed.), Language Testing Research Colloquium. Validation in language assessment: Selected papers from 17th Language Testing Research Colloquium (p. 41-60). Lawrence Erlbaum Associates Publishers.

Read, J. (2000). Assessing vocabulary. Cambridge University Press.

Read, J. (2004). Plumbing the depths: How should the construct of vocabulary knowledge be defined? In B. Harley, \& J. H. Hulstijn (Eds.), Language learning and language teaching. Vocabulary in a second language: Selection, acquisition and testing (vol. 10, pp. 209-227). John Benjamins Publishing Company.

Rezaei, A., Mai, N., \& Pesaranghader, A. (2014). The effect of mobile applications on English vocabulary acquisition. Jurnal Teknologi, 68(2), 73-83. https://doi.org/10.11113/JT.V68.2912

Richards,J.C.(1976).The role of vocabulary teaching.TESOL Quarterly, 10,77-89.https://doi.org/10.2307/3585941

Rydland, V., Aukrust, V. G., \&Fulland, H. (2012). How word decoding, vocabulary and prior topic knowledge predict reading comprehension: A study of language minority students in Norwegian fifth grade classrooms. Journal of Reading and Writing, 25(2), 465-482. https://doi.org/10.1007/s11145-010-9279-2

Saran, M., \& Seferoglu, G. (2010). Supporting foreign language vocabulary learning through multimedia messages via mobile phones. Hacettepe University Journal of Education, 38, 252-266.

Saran, M., Seferoglu, G., \& Cagiltay, K. (2012). Mobile language learning: Contribution of multimedia messages via mobile phones in consolidating vocabulary. The Asia-Pacific Education Researcher, 21(1), 181-190.

Saricoban, A., Ozturan, T. (2013). Vocabulary learning on move: An investigation of mobile assisted vocabulary learning effect over students` success and attitude. EKEV Academic Journal, 17 (54), 213-224.

Shen, Z. (2008). The roles of depth and breadth of vocabulary knowledge in EFL reading performance. Asian Social Science, 4 (12), 135-137. https://doi.org/10.5539/ass.v4n12p135

Schmitt, N., \& Schmitt, D. R. (1995). Vocabulary notebooks: Theoretical underpinnings and practical suggestions. English Language Teaching Journal, 49(2), 133-143. https://doi.org/10.1093/elt/49.2.133

Schmitt, N. (2000). Vocabulary in language teaching. Cambridge University Press.

Schmitt, N. (2008). Review article: Instructed second language vocabulary learning. Language Teaching Research, 12(3), 329-363. https://doi.org/10.1177\%2F1362168808089921

Schmitt, N., \& Meara, P. (1997). Researching vocabulary through a word knowledge framework: Word associations and verbal suffixes. Studies in Second Language Acquisition 19(1), 17-36. https://doi.org/10.1017/ S0272263197001022

Schmitt, N., \& Schmitt, D., \& Clapham, C. (2001). Developing and exploring the behavior of two new versions of the vocabulary levels test. Language Testing, 18(1), 55-88. https://doi.org/10.1177\%2F026553220101800103

Schmitt, N. 2014. Size and depth of vocabulary knowledge: What the research shows. Language Learning, 64(4), 913-951. https://doi.org/10.1111/lang.12077

Schoonen, R., \& Verhallen, M. (2008). The assessment of deep word knowledge in young first and second language learners. Language Testing, 25, 211-236. https://doi.org/10.1177/0265532207086782

Stæhr, L. S. (2009). Vocabulary knowledge and advanced listening comprehension in English as a foreign language. Studies in Second Language Acquisition, 31(4), 577-607. https://doi.org/10.1017/S0272263109990039

Stockwell, G. (2007). Vocabulary on the move: Investigating an intelligent mobile phone-based vocabulary tutor. Computer-Assisted Language Learning, 20(4), 365-83. https://doi.org/10.1080/09588220701745817

Stockwell, G. (2008). Investigating learner preparedness for and usage patterns of mobile learning. ReCALL 20(3), 253-270. https://doi.org/10.1017/S0958344008000232

Stockwell, G. (2010). Using mobile phones for vocabulary activities: Examining the effect of the platform. Language Learning \& Technology, 14(2), 95-110.

Stošić, L., \& Bogdanović, M. (2013). M-learning-a new form of learning and education. International Journal of Cognitive Research in Science, Engineering and Education, 1(2), 114-118.

Sutarsyah, C., Nation, I. S. P., \& Kennedy, G. (1994). How useful is EAP vocabulary for ESP? A corpus based study. RELC Journal, 25(2), 34-50. https://doi.org/10.1177\%2F003368829402500203

Suwantarathip, O., \& Orawiwatnakul, W. (2015). Using mobile-assisted exercises to support students' vocabulary skill development. Turkish Online Journal of Educational Technology, 14(1), 163-171.

Tabatabaei, O., \& Goojani, A. (2012). The impact of text messaging on vocabulary learning of Iranian EFL learners. Cross Cultural Communication, 8(2), 47-55. https://doi.org/10.3968/J.CCC.1923670020120802.1689

Thornton, P., \& Houser, C. (2005). Using mobile phones in English education in Japan. Journal of Computer- 
Assisted Learning, 21(3), 217-228. https//doi.org/10.1111/j.1365-2729.2005. 00129.x

Thorndike, E. L., \& Lorge, I. (1944). The teacher's word book of 30000 words. Columbia University.

Todd, R. W., \& Tepsuriwong, S. (2008). Mobile mazes: Investigating a mobile phone game for language learning. CALL-EJ, 9(1), 1-10.

Tomita, D. (2009). Text messaging and implications for its use in education. In TCC Proceedings (pp. 184-193). TCCHawaii.

Vermeer, A. (2001). Breadth and depth of vocabulary in relation to L1/L2 acquisition and frequency of input. Applied Psycholinguistics, 22, 217-34. https//doi.org/10.1017/S0142716401002041

Wang, B. T. (2017). Designing mobile apps for English vocabulary learning. International Journal of Information and Education Technology, 7(4), 279-283.

Wang, Y. H., \& Shih, S. K. H. (2015). Mobile-assisted language learning: Effects on EFL vocabulary learning. International Journal of Mobile Communications, 13(4), 358-375. https://doi.org/10.1504/IJMC.2015.070060

Webb, S., Sasao, Y., \& Ballance, O. (2017). The updated vocabulary levels test: Developing and validating two new forms of the VLT. ITL-International Journal of Applied Linguistics, 168(1), 34-70. https://doi.org/10.1075/ itl.168.1.02web

Wesche, M., \& Paribakhat, T. S. (1996). Assessing second language vocabulary knowledge: Depth versus breadth. Canadian Modern Language Review, 53(1), 13-40.

West, M. (1953). A general service list of English words. Longman.

Wong, L. -H., \& Looi, C. -K. (2010). Vocabulary learning by mobile-assisted authentic content creation and social meaning-making: Two case studies. Journal of Computer Assisted Learning, 26(5), 421-433.

Wu, Q. (2015). Pulling mobile assisted language learning (MALL) into the mainstream: MALL in broad practice. PloS One, 10(5), e0128762. https://doi.org/10.1371/journal.pone.0128762

Xue, G., \& Nation, I. S. P. (1984). A university word list. Language Learning and Communication, 3(2), 215-229.

Zareva, A. (2005). Models of lexical knowledge assessment of second language learners of English at higher levels of language proficiency. System, 33(4), 547-562. https://doi.org/10.1016/j.system.2005.03.005

Zhang, L. J., \& Annual, S. B. (2008). The role of vocabulary in reading comprehension. RELC, 39(1), 51-76.

Zhang, H., Song, W., \& Burston, J. (2011). Reexamining the effectiveness of vocabulary learning via mobile phones. Turkish Online Journal of Educational Technology, 10(3), 203-214. 